\title{
Evaluating delays for emergent CT scans from a rural British Columbia hospital
}

\author{
Adam Watchorn $^{1,2,3}$ [D Jason Curran ${ }^{2} \cdot$ Zoe Evans $^{2,3} \cdot$ Vanessa Wong $^{1}$
}

Received: 27 January 2021 / Accepted: 11 May 2021 / Published online: 22 June 2021

(c) The Author(s), under exclusive licence to Canadian Association of Emergency Physicians (CAEP)/ Association Canadienne de Médecine d'Urgence (ACMU) 2021

\begin{abstract}
Objectives Computed Tomography (CT) scans help diagnose and triage life-threatening and time-sensitive emergency conditions, but most rural hospitals in British Columbia do not have access to a local CT scanner. We investigate how many transfers from a rural British Columbia hospital were for CT scans and describe the time delays to emergent CT imaging.

Methods This was a prospective cohort study, over a 1-year period, on all patients requiring a transfer from the Golden and District Hospital, located $247 \mathrm{~km}$ from the closest CT scanner. Data collection forms were completed prospectively and the main measurements included age, transport triage level, reason for transfer, referral hospital, transfer request time, and CT scan time. The time interval between the CT request and CT imaging was calculated and represents the 'delay to CT scan' interval.

Results The study hospital received 8672 emergency department (ED) visits and 220 were transferred to referral centres (2.5\%). $61 \%$ of all transfers received a CT scan. Transfers for time-sensitive emergencies took an average of $6 \mathrm{~h} 52 \mathrm{~min}$. Patients with acute stroke experienced a $4 \mathrm{~h} 44$ min time interval. Less urgent and non-urgent conditions entailed an even greater time delay.

Conclusions This study highlights that the lack of a rural CT scanner is associated with increased transfers and significant time delays. Improving access to CT scanners for rural communities may be one of the many steps in addressing healthcare disparities between rural and urban communities.
\end{abstract}

Keywords Inter-facility transport/transfer · Computed Tomography (CT) scans $\cdot$ Rural health services $\cdot$ Equity $\cdot$ Access · Emergency department

Adam Watchorn

adamwatchorn@gmail.com

University of British Columbia, Vancouver, BC, Canada

2 Interior Health Authority, Kelowna, BC, Canada

3 Golden and District Hospital, 8359 Ave S, Golden, BC V0A 1H0, Canada 


\section{Résumé}

Objectifs La tomodensitométrie (TDM) aide à diagnostiquer et à trier les situations d'urgence qui mettent la vie en danger et pour lesquelles le temps est compté, mais la plupart des hôpitaux ruraux de la Colombie-Britannique n'ont pas accès à un tomodensitomètre local. Nous enquêtons sur le nombre de transferts d'un hôpital rural de la Colombie-Britannique pour des tomodensitogrammes et nous décrivons les délais pour l'imagerie tomographique émergente.

Méthodes Il s'agit d'une étude de cohorte prospective, sur une période d'un an, sur tous les patients nécessitant un transfert de l'hôpital de Golden and district, situé à $247 \mathrm{~km}$ du scanner le plus proche. Les formulaires de collecte de données ont été remplis de manière prospective et les principales mesures comprenaient l'âge, le niveau de triage de transport, la raison du transfert, l'hôpital de référence, le temps de demande de transfert et le temps de tomodensitométrie. L'intervalle de temps entre la demande de tomodensitométrie et l'imagerie par tomodensitométrie a été calculé et représente l'intervalle « retard au scanner».

Résultats L'hôpital d'étude a reçu 8672 visites aux services d'urgence (SU) et 220 ont été transférés aux centres d'aiguillage $(2,5 \%)$. $61 \%$ de tous les transferts ont fait l'objet d'un scanner. Les transferts pour les urgences sensibles au facteur temps ont pris en moyenne $6 \mathrm{~h} 52$. Les patients ayant subi un accident vasculaire cérébral aigu ont connu un intervalle de temps de $4 \mathrm{~h} 44$. Des conditions moins urgentes et non urgentes ont entraîné un délai encore plus long.

Conclusions Cette étude met en évidence que l'absence de tomodensitomètre en milieu rural est associée à une augmentation des transferts et à des retards importants. L'amélioration de l'accès aux tomodensitomètres pour les communautés rurales peut être l'une des nombreuses étapes pour remédier aux disparités en matière de soins de santé entre les communautés rurales et urbaines.

\section{Clinician's capsule}

What is known about the topic?

There is a lack of CT scanners in rural hospitals meaning potentially long transfers for patients requiring emergent $\mathrm{CT}$ scans.

\section{What did this study ask?}

How many transfers from a rural hospital were for CT scans and how long were the delays for emergent CT scans.

\section{What did this study find?}

$61 \%$ of total transfers were for CT scans and CT scan delays for emergent conditions averaged $6 \mathrm{~h}$ $52 \mathrm{~min}$.

\section{Why does this study matter to clinicians?}

Emergent CT scans' delays may cause negative outcomes; highlighting the need for greater access to CT scans in rural Canada.
Timely access to a computed tomography (CT) scan is critical to diagnose and triage patients with life-threatening illnesses. In B.C., CT scanners are generally located in regional or tertiary hospitals. Only $3 \%$ of rural B.C. hospitals have access to a local CT scanner compared to $15 \%$ and $70 \%$ of Ontario and Quebec rural hospitals, respectively [2, 4]. Patients in rural hospitals requiring an emergent $\mathrm{CT}$ scan must be transferred oftentimes hundreds of kilometers away.

Given the geography, weather, and limited transport resources in rural B.C., transfers can be challenging. They are also associated with a risk of clinical deterioration, intratransfer adverse events, and delays in time-sensitive care [3-5].

A multi-centre study from rural Ontario showed that $14 \%$ of transfers for were CT scans [6]. However, this study is dated and there remains a lack of recent evidence on this topic. To date, there are no studies examining transfer time intervals for CT scans from rural hospitals. The objective of this study is to investigate how many transfers from a rural B.C. hospital were for CT scans and describe the time delays to emergent $\mathrm{CT}$ imaging.

\section{Methods}

\section{Study design}

Approximately $14 \%$ of the British Columbia (B.C.) population lives in rural or remote areas [1]. The provision of emergency care in rural and remote areas is challenging. Apart from basic laboratory and X-ray services, most rural EDs in B.C. and Canada have limited access to local specialist support, advanced imaging, and critical care services [2-4].
This prospective cohort study examined all patients requiring transfer to another hospital between November 2017 and November 2018. Those patients who received a CT scan at the referral hospital were the focus of the analysis. There are no electronic data systems in B.C. with patient transport data; therefore, data collection forms were completed 
by the most responsible nurse or physician at the time of transfer. Data were manually extracted from the patient's chart and included date, age, sex, reason for transfer, referral hospital, transfer request time, departure time, and mode of transport. Patient CT reports were manually extracted by the principal investigator from the electronic medical record (MEDITECH) used by the Interior Health Authority. These reports provided us with the $\mathrm{CT}$ image interpretation time, type of CT scan, and results.

Every transfer was reviewed by the principal investigator and co-investigator to determine if the transfer could have been avoided if a local CT scanner was available. Avoidable transfers were defined by the following criteria: (1) CT scan was normal and the patient did not require admission or specialist consult at the referral hospital and was discharged; or, (2) CT scan was abnormal, but could have been managed locally at the study hospital.

Each inter-facility patient transfer was given a colourcoded triage level to prioritize patient movement between facilities within B.C. 'Red' indicating emergent and time sensitive; 'yellow' representing urgent and time sensitive; and, 'green' as non-urgent transfers. Outpatient CT scans and any patient transferred by private vehicle were excluded. The study protocol was approved by the Interior Health Authority research ethics board (2017-18-038-I).

\section{Study setting}

The Golden and District Hospital in Golden, B.C., is a rural hospital servicing a population of 6856 ; median age of 40 years. The hospital offers services including inpatient, obstetrics, and 24/7 emergency. Diagnostic services consist of laboratory, X-ray and ultrasound. The nearest trauma center is located $264 \mathrm{~km}$ away in Calgary, Alberta, while the nearest CT scanner is in Cranbrook, B.C., $247 \mathrm{~km}$ from the study hospital [Online Supplement Fig. 1]. The study hospital's ED has similar annual visits and remoteness to other rural hospitals in B.C. and Canada [2, 3].

\section{Data analysis}

All data were inputted, cleaned, and managed in Microsoft Excel (version 16.37). The total number of transfers and the number of transfers that received CT imaging were calculated. The time intervals between the $\mathrm{CT}$ requests and the actual CT image were calculated and represent the 'delay to CT scan' interval. The primary outcome is the proportion of transfers for CT scans and the secondary outcome, the time delays to emergent $\mathrm{CT}$ imaging.
Table 1 Time interval between CT scan ordered in rural hospital to CT scan completion (in hours: minutes)

\begin{tabular}{lllll}
\hline Transfer triage & Mean & SD & Min & Max \\
\hline Emergent (red) & $6: 52$ & $3: 09$ & $3: 23$ & $13: 58$ \\
Acute strokes & $4: 44$ & $0: 56$ & $3: 33$ & $6: 21$ \\
Urgent (yellow) & $8: 52$ & $3: 49$ & $4: 30$ & $20: 00$ \\
Non-urgent (green) & $16: 36$ & $7: 21$ & $4: 09$ & $29: 30$ \\
\hline
\end{tabular}

\section{Results}

During the study period, the study hospital had 8672 ED visits and 223 transfers. Three of these transfers had incomplete data points, thus; a total of 220 patient transfers were included in the study (2.5\% of total ED visits). The mean age was 48 years, $60 \%$ were male, the main diagnosis was trauma (including orthopedics) (Online Supplement Fig. 2], and the most common exam performed was CT head [Online Supplement Table 1].

\section{CT scan transfer time intervals}

The 'delay to CT scan' interval was calculated (Table 1). Of note, the average time interval for a patient designated a 'red' transfer was $6 \mathrm{~h}$ and $52 \mathrm{~min}$. The average time interval for acute strokes (a subset of 'red' transfers) was $4 \mathrm{~h}$ and 44 min.

\section{CT scan transfers}

135 patients received a $\mathrm{CT}$ scan at the referral centre (61\% of all transfers). $19 \%$ of the transfers were designated 'red'; 54\% 'yellow'; and, 27\% 'green' [Online Supplement Fig. 3]. $92 \%$ of these patients were transferred by ground and 8 percent $(8 \%)$ by air. Of the ground transfers, $86 \%$ were performed by primary care paramedics from BCEHS. Acute strokes comprised $4 \%$ of total transfers.

Based on the criteria outlined in the methods, if the study hospital had a local CT scanner, 84 transfers could have been avoided ( $38 \%$ of total transfers).

\section{Discussion}

\section{Interpretation of findings}

This study shows significant delays to emergent CT scans from this rural B.C. hospital. Even though the "golden hour" of trauma and emergency care is largely 
unsubstantiated, a nearly 7-h delay to CT scan for a timesensitive condition may present the potential for negative outcomes [2].

The delay to CT for acute strokes ranged between $3 \mathrm{~h}$ $33 \mathrm{~min}$ to $6 \mathrm{~h} 21 \mathrm{~min}$. This would result in the majority of acute stroke patients falling outside the 'time window' for beneficial treatment. Not surprisingly, rural hospitals may not meet recent standards for acute stroke care resulting in poorer outcomes than urban hospitals. This was recently highlighted by a Canadian study showing 30-day in-hospital mortality rates following stroke were higher in rural than in urban hospitals [7].

Close to $40 \%$ of the total transfers could have been avoided with a local CT scanner decreasing the burden on transport and referral hospital resources, and benefitting patients by staying local. The first rural CT scanner in Walkerton, Ontario was shown to provide faster access to diagnosis, higher confidence in diagnosis, quicker treatments, and help narrow the gap between urban and rural levels of health care [8].

\section{Comparison to previous studies}

There are no comparison studies looking at transfer time intervals for patients requiring CT scans. A Canadian study showed that patients arrive at Level 1 trauma centres an average of $6 \mathrm{~h}$ after presenting to a rural centre, and the risk of trauma death is threefold higher in rural than in urban settings [9]. We could not find any studies describing transfer time intervals for acute strokes from rural Canada or elsewhere.

The study hospital transferred $2.5 \%$ of patients, which is consistent with approximately $3 \%$ cited in the literature in the past 10 years $[4,5,7]$. The proportion of patients who received a CT scan is much higher than a multi-centre study out of rural Ontario; however, this study is 20 years old when the practice of ordering CT scans was less frequent [6].

\section{Limitations}

This study provides a one-year snapshot of inter-facility transfers from a single rural hospital. Although our hospital has similar characteristics to others in rural B.C. and Canada $[2,3]$ the findings may not be representative of other rural hospitals. Time intervals to CT scans may be affected by other factors at referral hospitals such as further investigations or active resuscitation.

\section{Conclusion}

This is the first study to track time intervals and characterize inter-facility transfers from a rural to urban hospital in B.C. We found a large proportion of transfers received CT scans and the delays for emergent CT scans were long. These delays may cause negative outcomes. In 1997, the Canadian Association of Emergency Physicians (CAEP) recommended that $\mathrm{CT}$ scanners should be more available in rural Canada [10]. Unfortunately, almost 25 years later, we still see a rural-urban disparity in access to CT scans. Future research addressing inter-facility transfers for CT scans and patient outcomes would be helpful for further health policy and services planning.

Supplementary Information The online version contains supplementary material available at https://doi.org/10.1007/s43678-021-00147-2.

Acknowledgements The authors would like to acknowledge the Rural Coordination Centre of British Columbia (RCCbc) for funding and general support. We would also like to extend appreciation to Dr. Richard Fleet for providing helpful feedback on the development of this article. Finally, we would also like to recognize the nurses, unit clerks, and physicians at the Golden and District Hospital for their assistance in the data gathering process.

Author contributions Adam Watchorn: 65\% (study design, data collection, initial analysis, manuscript development). Jason Curran: $25 \%$ (analysis, manuscript development, editing). Zoe Evans: 5\% (data collection). Vanessa Wong: 5\% (manuscript development and formatting).

Funding The Rural Coordination Centre of British Columbia (RCCbc) provided funding and support for this project.

\section{Declarations}

Conflict of interest None.

Ethics approval Interior Health Authority research ethics board (201718-038-I)

Consent for publication Authors provide consent for publication.

\section{References}

1. Statistics Canada. Canada's rural population since 1851 population and dwelling counts, 2011 Census. 2011;(2):5.

2. Fleet R, Audette L-D, Marcoux J, Villa J, Archambault P, Poitras J. Comparison of access to services in rural emergency departments in Quebec and British Columbia. CJEM. 2014;16(06):437-48.

3. Fleet R, Poitras J, Maltais-Giguère J, Villa J, Archambault P. A descriptive study of access to services in a random sample of Canadian rural emergency departments. BMJ Open. 2013;3(11):e003876. 
4. Bergeron C, Fleet R, Tounkara FK, Lavallée-Bourget I, TurgeonPelchat C. Lack of CT scanner in a rural emergency department increases inter-facility transfers: a pilot study. BMC Res Notes [Internet]. 2017 Dec 28 [cited 2020 Jul 19];10. 3(11):e003876. Available from https://www.ncbi.nlm.nih.gov/pmc/articles/ PMC5745590/

5. Feazel L, Schlichting AB, Bell GR, Shane DM, Ahmed A, Faine $\mathrm{B}$, Nugent A, Mohr NM. Achieving regionalization through rural interhospital transfer. Am J Emerg Med. 2015;33(9):1288-96. https://doi.org/10.1016/j.ajem.2015.05.032.

6. Rourke JTB, Kennard M. Emergency patient transfers from rural hospitals: a regional study. Can J Emerg Med. 2001;3(4):296-301.

7. Fleet R, Bussières $S$, Tounkara FK, Turcotte $S$, Légaré $F$, Plant J, et al. Rural versus urban academic hospital mortality following stroke in Canada. PLoS One [Internet]. 2018 Jan 31 [cited 2020 Nov 30];13(1). Available from https://www.ncbi.nlm.nih.gov/ pmc/articles/PMC5791969/

8. Merkens BJ, Mowbray RD, Creeden L, Engels PT, Rothwell DM, Chan BT, et al. A rural CT scanner: evaluating the effect on local health care. Can Assoc Radiol J. 2006;57(4):224-31.

9. Gomez D, Berube M, Xiong W, Ahmed N, Haas B, Schuurman $\mathrm{N}$, et al. Identifying targets for potential interventions to reduce rural trauma deaths: a population-based analysis. J Trauma Acute Care Surg. 2010;69(3):633-9.

10. Canadian Association of Emergency Physicians. Recommendations for the management of rural, remote, and isolated emergency health care facilities in Canada. J Emerg Med. 1997;15(5):741-7. 